\title{
MODELS OF IT-PROJECT MANAGEMENT
}

\author{
Julia Doronina and Ekaterina Doronina \\ Department of Information Systems, Sevastopol State University, Sevastopol, Russian \\ Federation
}

\begin{abstract}
Information system project management (IT - project) is a complex iterative process. An important role for the development of complex IT projects plays records of the development lifecycle (LC). The article presents an analysis of the effectiveness of the work on the creation of IT-projects based on two modified models of the life cycle: cascade and spiral. Analysis of the effectiveness of the management of the IT project was implemented on the basis of simulation. The modeling was carried out on the basis of Any Ljgic tools on the example of development of geoinformation system (GIS). It is shown that it is advisable to design GIS on the basis of a modified spiral LC with splitting of the flow of requirements at the input. The peculiarity of the proposed study is to take into account the requirements in the form of communicative interactions of different types. Under the communicative interactions are understood all the interactions between the subjects of the process of creating an IT-project: verbal and non-verbal, carried out on the basis of CASE-means.
\end{abstract}

\section{Keywords}

Information System (IS), Geographic Information System (Gis), Organizational Management, Communication Processes, Modeling, IT - Project Management.

\section{INTRODUCTION}

Requirements for information and geo information systems (IS and GIS) as the implementation of the IT - project are growing, as the areas of application of these systems are becoming more complex. In the implementation of the IT-project plays an important role in the development of approaches to assessing the effectiveness of these systems. The complexity of the systems contributes to the complexity of the processes of design, modeling, design and other works on their creation. Each type of activity is accompanied by communicative processes, expressed in the exchange of information, both verbal and software (interface) levels. Features of the processes of design, construction and maintenance of IT-project are:

1. multilanguage design and construction of IS (many languages of modeling, programming, design, including natural languages in which subjects communicate, for example, in the development of technical specifications);

2. multilanguage interaction of subjects of the process (including different levels of specialization of subjects);

3. the complexity of the process of system integration (including due to the many platforms for the implementation of individual subsystems of the IT - project).

The problem of multilingual and multi-communicative information exchange is solved by the subjects using a multi-model approach integrating different levels of their interaction [1]. 
International Journal of Computer Science \& Information Technology (IJCSIT) Vol 10, No 5, October 2018

\section{OVERVIEW OF IT - PROJECT MANAGEMENT APPROACHES}

Project management can be implemented based on various existing techniques. Scrum is an approach to project development that does not require filling out a multi-page technical specification, as in the standard model. For the first time a new approach to the development of the project was described by Ikujiro Nonaka and Hirotaka Takeuchi in their joint article The New Product Development Game, published in the Harvard business Review in the winter of 1986. In the early 1990s, Ken Schwaber and Jeff Sutherland described, documented and successfully applied the new approach in detail. [2] The technique is called - Scrum. Scrum is a methodology for managing the development of information systems, which places a strong emphasis on the quality control of the development process. In addition to managing software development projects, the methodology is used by software support teams, as well as an approach to managing software development and maintenance.

There are 3 basic roles in classic Scrum:

- Product owner $(\mathrm{PO})$ - is a link between the development team and the customer. The goal of $\mathrm{PO}$ is to maximize the value of the product being developed and the work of the team. One of the main tools of PO is Product Backlog. The Product Backlog contains the necessary work tasks (such as Story, Bug, Task, etc.), sorted in order of priority (urgency);

- Scrum master (SM) is a servant-leader. The goal of Scrum Master is to help the team maximize its effectiveness by removing obstacles, helping, training and motivating the team, helping PO;

- Development team (DT) comprised of professionals engaged in direct work-product.

Another well - known method of IT project management is DSDM (Dynamic Systems Development Method) [3]. The process begins with a study of the feasibility of the programme and its application. The process is further divided into three interrelated cycles: the functional model cycle is responsible for creating analytical documentation and prototypes, the design and construction cycle is responsible for bringing the system into working condition, and finally, the last cycle - the implementation cycle - ensures the deployment of the software system. The basic principles on which DSDM is based are active interaction with users, frequent releases of versions, independence of developers in decision-making and testing during the whole cycle of work.

The methodology (briefly referred to as FDD) was developed by Jeff De Luca and Peter Coad. Like other adaptive methodologies, it is implemented in short iterations, each of which is used to develop a certain part of the system functionality. According to FDD, one iteration lasts two weeks. FDD has five processes: the development of a General model, the compilation of a list of required properties of the system, the planning of work on each property, the design of each property, the construction of each property [4].

The method of Kanban software development was invented by David Anderson. Many of these practices and approaches were used by different Agile teams before being described by David as a whole. Kanban " Kan "- visible, visual; " ban " - card or Board), a Japanese term known for Toyota's production system, the basic principles of which are: lean manufacturing, continuous development, customer orientation, etc. [5,6]

Thus, the existing approaches to project management are implemented in the majority of planning based on the graphic capabilities of the software. 
International Journal of Computer Science \& Information Technology (IJCSIT) Vol 10, No 5, October 2018

But when implementing an IT- project, it is necessary to take into account the dynamic requirements arising in the design process. In connection with the presence of these problems in large corporations adopt common languages of communication in the framework of platform design [7,9]. Communication problems are reflected in the information exchange, which leads to the problem of design in General [9]. Due to the fact that excessive communication processes increase the cost and reduce the speed of implementation, and an insufficient level of information interaction can lead to a decrease in the quality of development, research aimed at creating a method of evaluation of the IT project based on the analysis of communication processes in order to improve the efficiency of design and operation of these systems are relevant.

\subsection{The Definition Of The Communication Process When Designing A System}

Communication many associated with the subjects of the creation of IS is defined as the basic (integrated) many of the languages of communication: $L=\left\{L_{T}, L_{P}, L_{S}\right\}$, where $L_{T}$ - the language of technology; $L_{P}$-the language designers; $L_{S}$ - the language specialists. It is assumed that these are generalized sets of languages. Knowledge of natural language is a priori established. Many stages of IP creation, or communication objects in a simplified form: $E=\left\{E_{T}, E_{P}, E_{S}\right\}$, where $E_{P}$-the design stage; $E_{T}$ - the stage of technology creation; $E_{S}$ - the stage of work of narrow specialists in the formation of technical specifications (TS) for the product or system. Many are mapped to $\mathrm{L}$ and $\mathrm{E}$ (without taking into account the sequence of the interaction) as a set of actors (in many languages) and many objects of communication.

There are a number of contradictions in the analysis of this correspondence:

1. between the requirement to" transparency" of interaction, i.e. knowledge of all languages by all subjects of communicative process at creation of is and optimization of organizational management of these processes on the basis of minimization of interactions;

2. between clear formulations of TS and fuzzy ways of forming decisions on the implementation of TS, as a reaction to the subject uncertainty expressed by communicative redundancy.

Thus, there is a problem of uncertainty of communicative communications and its elimination is required. In addition, based on the definition of the criterion of the effectiveness of individual communication, it is possible to determine the effectiveness of the process of interaction of subjects in the creation of IP in General. Such criteria may be the cost and flexibility of the organizational management process.

It is proposed to identify the basic (reference) communication between the languages and stages of the project $L_{T} \rightarrow E_{T}, L_{P} \rightarrow E_{P}, L_{S} \rightarrow E_{S}$ and put it in line with the process of the product life cycle (system), that is, to organize the stages of the LC of a particular product (Product Lifecycle Management). In fact, it means defining the basic communication process of a particular IS: $K^{i}, i=\overline{1, I}$. Based on this, it is possible to obtain a description of the communicative process characteristic of the stage-by-stage construction of the $i$ - th IS based on a simple cascade model.

The process of creating the IC is represented as a mapping of the design input data to the output result, taking into account the multi-version model: 
International Journal of Computer Science \& Information Technology (IJCSIT) Vol 10, No 5, October 2018

$$
X(t) \rightarrow Y(t)=\bigcup_{\forall \chi}\left(Z_{\chi}(t)\right),
$$

where $X(t)$ - the initial process associated with the definition of the initial data for the design, $Y(t)$ - the resulting process that determines the design of the system, $Z_{\chi}(t)$ - some version of the IS, based on a certain communicative process, $\quad \chi \in \overline{1, V}-$ the version number arising from the implementation of the new requirements in the new communicative process, $V$ - the total number of possible versions.

Multi-versioning makes it possible to take into account the formation of a plurality of mappings (or intermediate projects), which will create a so-called design field, which implements the communicative processes of different levels.

The cost of IS taking into account (1) is determined as follows

$$
\sigma\left(Z_{\chi}\right) \rightarrow \min _{\chi} \sigma\left(Z_{\chi}\right)=\min _{\chi} \sum_{k=1}^{Y a} \sigma_{k}\left[\left(\sum_{\chi_{k}=1}^{K_{k}} Z_{k_{\chi}}\right) l\left(\breve{\xi}_{j} \leq \bar{\xi}^{0}\right)\right], j=\overline{1, J},
$$

where $\sigma\left(Z_{\chi}\right)$ - cost $\chi$-version of the system, $\sigma_{k}$ - cost version of the system in the framework of the k-th communication, $\breve{\xi}_{j}$ - current limit $\chi$-version (control parameters) of the system (language of communication), $\xi^{0}$ - specified limit on the version (control parameters), $j=\overline{1, J}-$ a finite number of constraints on the parameters of the current version of the system, $Y a_{-}$a possible finite number of languages of communication in the design of this IS.

To build models, the concept of conditional communication (CC) is Introduced, which is a separate interaction of the conditional customer with the conditional Creator of the system within the current communication. Conditional customer (CCust) in the General case are: the head of the organization of the customer, technician, engineer, etc. is likewise defined by a Union Creator (UC), as the group of entities that implement the development of IS. That is, communications are no longer considered as a separate local interaction, but as the interaction of a subset of bonds with a subset of bonds, which will allow on the one hand to consolidate and standardize, as far as possible, communications, and on the other hand, to clarify and detail the description of interactions.

Example conditional communication:

1.A preliminary agreement on the creation of information systems

2.Preparation of the agreement of intent

3.Cooperation in the preparation of technical specifications

4.Discussion on the technical specifications

5.Start of work on the clarification of points of technical specifications

6.Approval of the subsection technical specifications

7.Clarification of the degree of adaptability systems to change methods managements

8.Definition of requirements for methods of reliability assessment.

9.Discussion of additional requirements

10. Harmonization of requirements for information support system

The content of conditional communication given as an example can be specified for each specific project. 
International Journal of Computer Science \& Information Technology (IJCSIT) Vol 10, No 5, October 2018

\subsection{Purpose And ObJectives Of The Study}

The aim of the study is to simulate the process of IT- project management by creating an information technology analysis of communication processes based on the organizational management system.

To achieve this goal, the following main tasks are formulated and solved:

- to offer a formalized description of communication processes for unification of information interactions of it project subjects with regard to their possible aggregation;

- for functional modeling of the information interaction of the subjects based on the analysis of business processes that reflect the communication links in the implementation of an it project;

- implementation of models and methods, conduct modeling and analysis of the results, reflecting the approaches to assessing the effectiveness of communication processes in the implementation of the IT- project.

\subsection{IMPLEMENTATION OF THE IT PROJECT MANAGEMENT PROCESS MODEL}

To model the management process of an it project on input and output data streams. The output flow can be understood as the flow of solved tasks that make up the information system. The input stream that represents the technical specification can include additional requirements or adjustments to them in accordance with the product Lifecycle Management (PLM) phases of a particular system [19].

The concept of conditional communication is introduced, which is a separate interaction of the conditional customer with the conditional Creator of the system within this communication. The conditional customer in General include: the head of the customer organization, technical worker, design engineer, i.e. a group of persons associated with the formation of the order for IS. Similarly, a conditional Creator is defined as a group of entities that implement IS development. That is, communications are no longer considered as a separate local interaction, but as the interaction of a subset of the conditional customer with a subset of the conditional Creator, which will allow on the one hand to enlarge and standardize, as far as possible, communications, and on the other hand, to clarify and detail the description of interactions. In the author's study, the formalization of communication in the creation of IS in the form of interaction between the conditional Creator and the conditional customer on the basis of specification of each conditional communication according to the technical specification.

In the analysis and modeling of organizational management processes it is advisable to fix the situation when conditional communication has passed all (or main) stages of the life cycle. It is proposed to apply the term "communication learning" as a complete life cycle communication. In order for all communications to be processed, it is necessary to complete their passage (assimilation of communication) at all stages of the life cycle branch.

Figures 1-2 show the results of modeling the stages of the is life cycle using a cascade model in AnyLogic [17]. The presented view of the model combines some of the qualities of the model shown in figure 4 (the response of the life cycle stages responsible for narrow specialization to the basic stages already at the initial iteration). However, the model shown is characterized by a significantly large number of redundant conditional communications at the input to achieve output values close to the values in the model in figure 4 . 


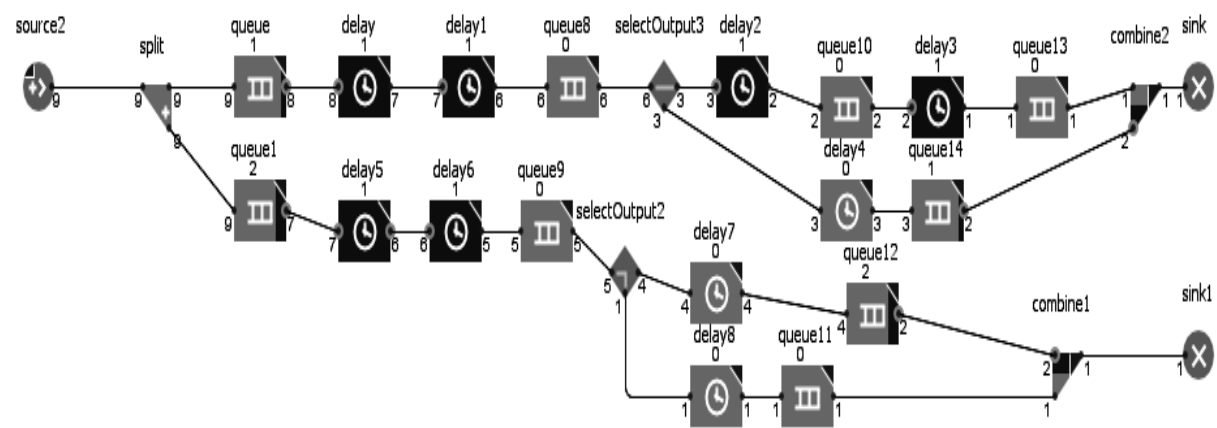

Figure 1. Model reflecting the type of information system life cycle based on the cascade model

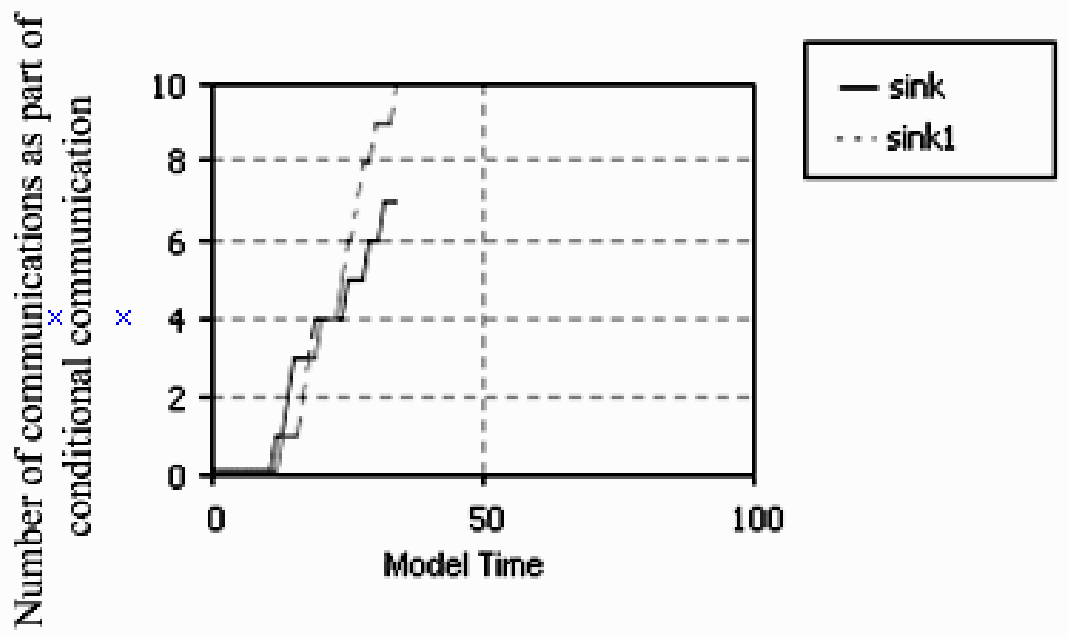

Figure 2. Diagram of sequential passing of conditional communications on stages of the life cycle of information system, based on the cascade model

The feature is shown in figure iteration of the cascade model represent the stages of the life cycle can be considered a advance stages of the life cycle specialization in relation to the base, which is interpreted as the interrelated work of the participants of the process of creating a complex system, that is, at the stage of development of preliminary design solutions on the system is parallel to the work on the system and its parts.

Figure 3-4 shows the scheme of the life cycle model of complex multi-level IS in AnyLogic [17] environment, formed on the basis of the scheme of IT- project creation processes. The model diagram represents several parallel branches of sequentially running operations. In terms of the environment, AnyLogic " delay "models the delay, the" queue "object models the queue of customers waiting for service, the" sink " group blocks indicate the end of the model scheme. The General type of model can be described as a Queuing system that performs maintenance of the requirements that come into it. The peculiarity of the model is that the splitting of the conditional communication package occurs in a cascade manner for each parallel line of sequential operations corresponding to the stages of the modified life cycle and conditional communications. However, because the spiral view of the life cycle model has been selected, an additional line of operations is introduced into the model. This requirement is implemented by a special queue14 block. The 
"combine" blocks collect split processed solution packages hierarchically across each conditional communication.

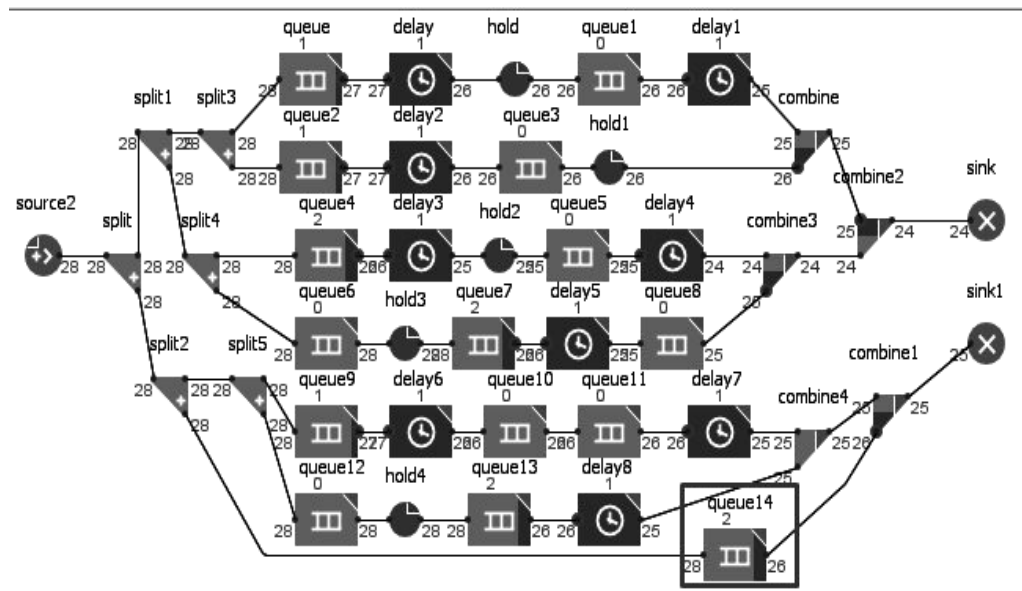

Figure 3. Model reflecting the type of information system life cycle based on of multi-level representation of stages of IT- project life cycle (spiral life cycle model)

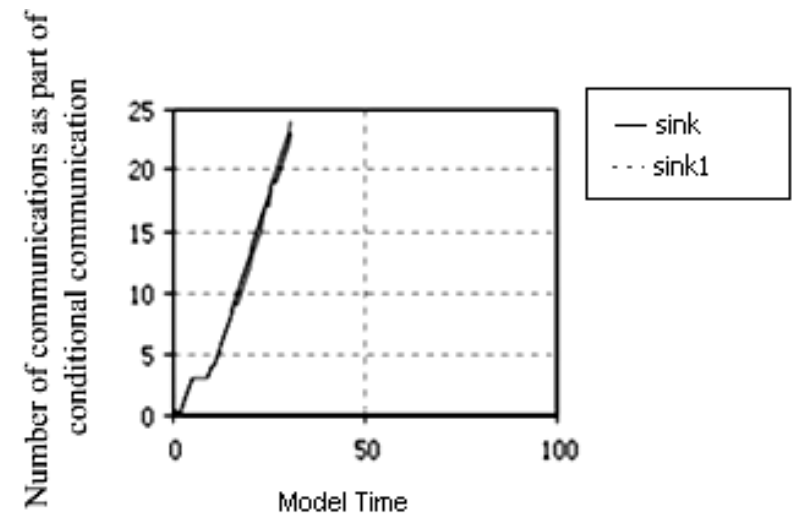

Figure 4. Diagram of sequential passing of conditional communications on stages of the life cycle of information system, based on the spiral life cycle model

To clarify the results of comparison of the obtained values of the processed problems, it was decided to choose the main results of the two types of models (based on the spiral life cycle and cascade life cycle). The results of the comparison are given in table 1 . The following features can be distinguished: the main results of the model built on the basis of the spiral life cycle exceed the values of the results of the run of the model based on the cascade life cycle, which indicates a lower efficiency of the latest model. However, the General tendency of accumulation of conditional communications to the extreme experiment is maintained in both models. 
Table 1. Comparison of the main simulation results with the spiral and cascade model of the modified life cycle.

\begin{tabular}{|c|c|c|c|c|c|c|}
\hline \multirow[t]{2}{*}{$\begin{array}{l}\text { Model block } \\
\text { name }\end{array}$} & \multicolumn{3}{|c|}{$\begin{array}{l}\text { Iterations of the spiral } \\
\text { life cycle model }\end{array}$} & \multicolumn{3}{|c|}{$\begin{array}{c}\text { Iterations of the } \\
\text { cascade life cycle model }\end{array}$} \\
\hline & 1 & 2 & 3 & 4 & 5 & 6 \\
\hline $\begin{array}{l}\text { Conventional } \\
\text { communications } \\
\text { on the input } \\
\text { (source) }\end{array}$ & 4 & 10 & 11 & 9 & 17 & 24 \\
\hline delay & 30 & 120 & 150 & 105 & 225 & 330 \\
\hline delay1 & 48 & 288 & 432 & 288 & 672 & 1008 \\
\hline delay2 & 126 & 1008 & 1260 & 252 & 630 & 882 \\
\hline delay3 & 36 & 252 & 324 & 36 & 180 & 252 \\
\hline delay4 & 7,5 & 45 & 60 & 22,5 & 60 & 105 \\
\hline delay5 & 42 & 294 & 420 & 252 & 630 & 966 \\
\hline delay6 & 48 & 384 & 480 & 240 & 720 & 1056 \\
\hline delay7 & 24 & 144 & 216 & 96 & 168 & 240 \\
\hline delay8 & 120 & 420 & 540 & 60 & 360 & 660 \\
\hline $\begin{array}{l}\text { Conventional } \\
\text { communications } \\
\text { on the output } \\
(\text { sink })\end{array}$ & 1 & 6 & 8 & 1 & 5 & 7 \\
\hline $\begin{array}{l}\text { Conventional } \\
\text { communications } \\
\text { on the output } \\
(\operatorname{sink} 1)\end{array}$ & 1 & 6 & 9 & 1 & 6 & 10 \\
\hline
\end{tabular}

The next stage of the study was to model the process taking into account the duration of the stages. Based on the results of the expert survey, time estimates of the duration of each stage of the IT - project life cycle were set for this purpose. Expert estimates of stage durations can be replaced by real or unique values in the model settings. The selected interaction of actors in the course of the description of the conditional communication has been mapped with well-defined stages of the life cycle of an IT - project. In fact, this means creating a set of compliance between the conditional customer and the conditional creator, taking into account the standardized stages of the IT - project life cycle.

The expertise was conducted by three experts in the field of information systems, programming and creation of large - scale IT projects. The analysis of the expert opinion consistency based on the concordance coefficient showed a sufficient level of consistency $(0.83)$.

Table 2 presents a comparison of the complexity and cost of the IT- project using a spiral model of the modified life cycle and a cascade model of the modified life cycle. It should be noted that the labor intensity values in both cases differ ambiguously, for example, at the stage corresponding to the block delay8, the values are equal, and at the stage delay3 the labor intensity value in the case of the cascade model is less.

The cost indicator of the entire project using a spiral life cycle model is 1381 conventional units; the cost indicator of the entire project using a cascade life cycle model is 1874 conventional units. 
Analysis of the simulation results associated with obtaining the numerical characteristics of complex processes that form the life cycle according to the requirements of the regulatory documentation will allow to make informed decisions based on updated quantitative estimates. This will make it possible to reduce the cost of IP. Thus, table 2 shows the calculated values of labor intensity and cost using cascade and spiral models of the modified life cycle. Labor intensity ratios were taken from [18], based on the experience of Oracle Corporation.

Table 2. Comparison of the complexity and cost of the IT- project project with the use of organizational management based on a spiral life cycle model and the use of a cascade model of the modified life cycle

\begin{tabular}{|c|c|c|c|}
\hline $\begin{array}{c}\text { Stages } \\
\text { creating an } \\
\text { IT- project }\end{array}$ & $\begin{array}{l}\text { Labor } \\
\text { input } \\
\text { factor }\end{array}$ & $\begin{array}{l}\text { Complexity of the stage } \\
\text { IT- project using a spiral } \\
\text { life cycle model }\end{array}$ & $\begin{array}{c}\text { Complexity of the } \\
\text { stage IT- project using } \\
\text { cascade life cycle } \\
\text { model }\end{array}$ \\
\hline delay & 0,2 & 60 & 132 \\
\hline delay1 & 0,5 & 384 & 984 \\
\hline delay2 & 0,6 & 1436,4 & 1058,4 \\
\hline delay3 & 0,4 & 244,8 & 187,2 \\
\hline delay4 & 0,1 & 11,25 & 18,75 \\
\hline delay5 & 0,4 & 302,4 & 739,2 \\
\hline delay6 & 0,5 & 456 & 1008 \\
\hline delay7 & 0,3 & 115,2 & 151,2 \\
\hline delay 8 & 0,5 & 540 & 540 \\
\hline \multirow[t]{2}{*}{$\begin{array}{c}\text { General } \\
\text { indicator } \\
\text { an IT- project }\end{array}$} & $\begin{array}{c}\text { Average } \\
\text { labor } \\
\text { input } \\
\text { ratio }\end{array}$ & $\begin{array}{l}\text { Complexity of the IT - } \\
\text { project using a spiral life } \\
\text { cycle model }\end{array}$ & $\begin{array}{l}\text { Complexity of the IT- } \\
\text { project using cascade } \\
\text { life cycle model }\end{array}$ \\
\hline & 0,39 & 3550,05 & 4818,75 \\
\hline
\end{tabular}

It is taken into account that the complexity directly affects the cost and risks of the project. The complexity of the application of the cascade model of the modified life cycle exceeds the complexity of the project management with the use of the spiral model of the modified life cycle at some stages by 2.7 times. The overall project complexity can be expressed in the labor costs calculated for each of the stages of project creation (in the model are marked as delayi) and lower by $20 \%$ when using the spiral life cycle model.

\subsection{ANALYSIS OF SIMULATION RESUlts TAKING INTO ACCOUNT THE INPUT OF ADDITIONAL BLOCKS INTO THE MODEL}

Further studies of the proposed models of it project management were carried out taking into account the introduction of additional blocks.

The model was modified by adding a block, based on the fact that each additional block meant additional communication. That is, the situation was modeled when in the process of creating the project there were additional requirements that had to be taken into account quickly. It has extended the communicative interaction of the subjects of the process. 
International Journal of Computer Science \& Information Technology (IJCSIT) Vol 10, No 5, October 2018

Table 3 Comparison of the main simulation results with additional blocks and the basic model

\begin{tabular}{|c|c|c|c|c|c|c|}
\hline \multirow{2}{*}{ Model block name } & \multicolumn{3}{|c|}{$\begin{array}{c}\text { Model without } \\
\text { additional block }\end{array}$} & \multicolumn{3}{c|}{ Model with additional } \\
block
\end{tabular}

Figure 5 shows the results of the comparison of the main results of the simulation with the additional units and the base model illustrate the following features: the main results of the basic model (without additional units) exceed the value of the results of the run of the model with additional blocks, which speaks more to the low efficiency of the latest model. This is due to the additional load due to the introduced delay blocks. However, the General tendency of accumulation of the performed ACS to the extreme experiment remains in both models.

Another General trend of the project is based on the results of modeling is the approximate equality of incoming to the input of the $\mathrm{CC}$ and processed $\mathrm{CC}$ at the output of each branch of the LC, which is noticeable in both models. The model parameters were selected in such a way that the output retained the same results in order to clarify the differences in the accumulation of delays in the model with additional blocks at specific stages with the current $\mathrm{CC}$. That is, the result is the same projects, but the number of communications and delays of these projects are different, which makes it possible to assess the causes of such developments in the design of IS.

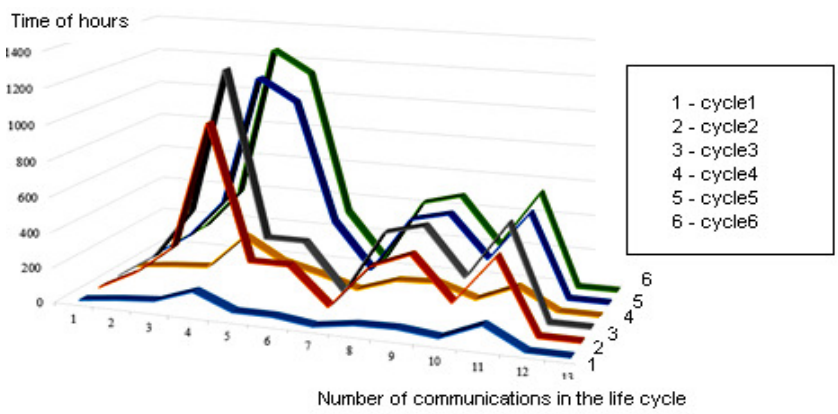

Figure 5. Diagram of the results of the comparison of the main results of the simulation with the additional units and the base model 
Table 4 presents a comparison of the average and total time spent on each of the stages of the LC (for 15 conditional communications, which corresponds to the standard set of stages of the LC), and table 5 shows the calculated values of the project cost indicator using spiral and cascade life cycle models.

Table 4. Comparison of average and total time taking into account additional units and the base model with the same parameters without using the model

\begin{tabular}{|c|c|c|c|}
\hline & $\begin{array}{c}\text { Model without } \\
\text { additional block }\end{array}$ & $\begin{array}{c}\text { Model with } \\
\text { additional block }\end{array}$ & $\begin{array}{c}\text { The simulation results } \\
\text { without the use of models } \\
\text { (the traditional approach) }\end{array}$ \\
\hline $\begin{array}{c}\text { Average time per } \\
\text { life cycle stage }\end{array}$ & 614,34 & 802,27 & 677,50 \\
\hline $\begin{array}{c}\text { Total } \\
\text { time for all life } \\
\text { cycle }\end{array}$ & 7986,50 & 10429,50 & 6097,50 \\
\hline
\end{tabular}

Table 5. Values of project cost indicators and $\mathrm{C}$ different life-cycle models

\begin{tabular}{|c|c|}
\hline $\begin{array}{c}\text { Indicator of the value of the project with } \\
\text { the IS of the application of the spiral model } \\
\text { life cycle }\end{array}$ & $\begin{array}{c}\text { Indicator of the value of the project IS } \\
\text { with the use of a waterfall model life } \\
\text { cycle }\end{array}$ \\
\hline 1381 & 1874 \\
\hline
\end{tabular}

According to the results given in table 5, it can be seen that without modeling, expert estimates underestimate the possible duration of the RC stages from $30 \%$ to $70 \%$ in complex cases.

It should be noted that the "complexity" is implemented by the introduction of additional blocks, which is not a critically difficult situation, but only reflects the real cases of additional requirements for the project and, accordingly, additional communication processes.

\section{CONClusions}

Features of implementation, for example, object-oriented programming are associated with a spiral model of the software life cycle, although the waterfall model is also acceptable for the development of an IT- project [20-21]. The paper [22] considers the method of modeling system dynamics, which corresponds to the General orientation of the presented work. In contrast to [22], the article proposes a complex model and studies the impact of the life cycle model on the management of system dynamics, taking into account the communicative processes. The constructed models, on which experiments are carried out, can be used to optimize the process of it project management. Testing of models showed their validity, and the solution of a specific problem taking into account the aggregated communication allowed to receive recommendations at creation of the plan of organizational management of the is project. The use of the proposed method will allow to calculate in advance the resource-intensive stages of the life cycle in the creation of IT- project, thereby improving the performance of the system. Thus, using expert assessments (only on the basis of experts ' experience), it is possible to underestimate the likely time load of the project up to $70 \%$. The cost of the entire project using a spiral life cycle model is 1.4 times lower than using a cascade model. Thus, the simulation has shown a more effective applicability of the modified spiral model in the management of the it-project of complex is, taking into account the specialization of its subsystems. 
International Journal of Computer Science \& Information Technology (IJCSIT) Vol 10, No 5, October 2018

\section{REFERENCES}

[1] B.V.Sokolov, R.M.Yusupov "Conceptual and methodological foundations of the qualimetry of models and polymodel complexes”, Proceedings of SPIIRAS, St.-Peterburg, 2004, Issue. 2, Volume 1, pp. 10-35.

[2] The Scrum Guide. The definitive Guide to Scrum: The Rules of the Game. Ken Schwaber, Jeff Sutherland. Режим доступа - http://www.scrumguides.org/ docs/scrumguide/v1/scrum-guide-us.pdf

[3] H. Kniberg, M. Skarin. Scrum and Kanban: push the maximum. C4Media, Publisher InfoQ.com Oh? Access mode - http://www.infoq.com/resource/ news/2010/01/kanban-scrumminibook/en/resources/KanbanAndScrum-Russian.pdf.

[4] The website of the consortium DSDM (Dynamic Systems Development Method). Access mode http://www.dsdm.org/.

[5] CyberGuru.EN. New programming methodologies. [Electronic resource] access Mode http://www.cyberguru.ru/programming/programming-theory/coding-methodology-new-page15.html

[6] Taiichi Ohno, "Toyota production system. Moving away from mass production", Library ICSI, Publisher: Institute for complex strategic studies, 2008, 194 p.

[7] “A guide to body of knowledge project management-PMI PMBOK”,Guide 5th Edition (2012), Mode - http://startupseminar.ru/_1d/0/17_301907_2D9D3_pm.pdf.

[8] "Microsoftöis: Project 2013 in project management by V. I. kuperstein", SPb.: BHV-Petersburg, 2014, 432 p.

[9] Y. A Ivashkin, "Multi-agent modeling in a simulation environment Simplex3: tutorial", Moscow: knowledge Laboratory, 2016, $350 \mathrm{p}$.

[10] G. V. Abramov, Medvedkova I. E., Korobov L. A. "Design of information systems: tutorial", Publisher: UGUET, 2012.

[11] Construction of work flow diagrams - WFD, URL: http://studopedia.info/2-82371.html.

[12] K.Larman, “Application of UML 2.0 and design patterns", Moscow: Williams, 2013, 736 p.

[13] M.Fowler, K. Beck, J.Brandt [et al.] "Refactoring. Improvement of existing code" M. Fowler, K. Beck, J. Brandt [et al.]. SPb. : Symbol-Plus, 2013, 432 p.

[14] A. David, Mark, Clement McGowan, "Structural analysis and design Methodology SADT", Metatechnology, 1993.

[15] "Creation of a corporate information system of a large enterprise" [Electronic resource]. URL: http://hr-portal.ru/article/sozdanie-korporativnoy-informacionnoy-sistemy-krupnogo-predpriyatiya.

[16] S. V. Zykov, 'Fundamentals of corporate systems design', National research University "Higher school of Economics" Ed. house of Higher school of Economics; Moscow, 2012.

[17] Official website of the company AnyLogic. URL: http://www.anylogic.com

[18] V. P. Koryachko, A. I. Taganov “ Processes and tasks project management of IP”, M, Hot line, Telecom, 2014, p.376.

[19] M.W. Grieves "Product lifecycle quality (PLQ): a framework within product lifecycle management (PLM) for achieving product quality", International Journal of Manufacturing Technology \& Management, 2010, T. 19, № 3-4, pp. 180-190.

[20] Nidhi Goyal1, Reena Srivastava Changeability evaluation model for object oriented software International Journal of Computer Science \& Information Technology (IJCSIT) Vol 9, No 4, August 2017, pp. 29-37.

[21] Anna Syberfeldt, Tom Ekblom A comparative evaluation of the gpu vs. the cpu for parallelization of evolutionary algorithms through multiple independent runs International Journal of Computer Science \& Information Technology (IJCSIT) Vol 9, No 3, June 2017, pp. 1-14. 
International Journal of Computer Science \& Information Technology (IJCSIT) Vol 10, No 5, October 2018

[22] Fadwa Chaker, Abdellah El Manouar, Mohammed Abdou Janati Idrissi Towards a system dynamics modeling method based on dematel International Journal of Computer Science \& Information Technology (IJCSIT) Vol 7, No 2, April 2015, pp. 27-40

\section{Authors}

Julia Doronina received the degree of Ph.D in Computer Science in 2014. Currently he is a Professor of Sevastopol state University (at the Department of information systems). Research interests include systems analysis, structural synthesis of complex systems and reengineering of information systems.

Ekaterina Doronina received a diploma at the Department of information systems at Sevastopol state University. He is currently working on modeling the processes of organizational management of IT projects. 
International Journal of Computer Science \& Information Technology (IJCSIT) Vol 10, No 5, October 2018

INTENTIONAL BLANK 